\title{
Experimental Analysis of the Feasibility of Shaving Process Applied for High-Strength Steel Sheets
}

\author{
Wiriyakorn Phanitwong, Arkarapon Sontamino, and Sutasn Thipprakmas \\ Department of Tool and Materials Engineering, King Mongkut's University of Technology Thonburi, Bangkok 10140, Thailand \\ Correspondence should be addressed to Wiriyakorn Phanitwong; wiriyakorn.wp@gmail.com
}

Received 24 March 2016; Revised 31 May 2016; Accepted 14 June 2016

Academic Editor: Jingwei Zhao

Copyright ( 2016 Wiriyakorn Phanitwong et al. This is an open access article distributed under the Creative Commons Attribution License, which permits unrestricted use, distribution, and reproduction in any medium, provided the original work is properly cited.

\begin{abstract}
In recent years, the engineered materials were developed to improve their mechanical properties. A high-strength steel sheet is one of them, developed to serve the requirement of reducing weight of vehicles. Therefore, as a new material, many researches have been carried out to examine the use of sheet metal forming process applied for high-strength steel sheet. However, the feasibility of shaving process applied for it has not been investigated yet. In the present study, this feasibility was revealed by using experiments on two types of high-strength steel sheets: SAPH 440 and SPFH 590Y (JIS). The relationship between shaved surface feature and shearing clearance of high-strength steel sheets corresponded well with those of their conventional metal sheets. However, due to the high ultimate strength of these materials, it was revealed in this present study that there were not any suitable conditions of shaving process that could be applied to achieve the requirements of smooth cut surface overall material thickness.
\end{abstract}

\section{Introduction}

In consideration of the fuel saving and thereby reducing of the $\mathrm{CO}_{2}$ exhaustion, in recent years, the decrease in weight of vehicles is focused on in the automotive industry. One of the means applied to meet this requirement is the more use of high-strength steel sheets as the automotive parts instead of the conventional steel sheets. As for the merits of high-strength steel sheet, its mechanical property of ultimate tensile strength could be increased over $1000 \mathrm{MPa}$ whereas the percentage of elongation could be maintained at the same level as that of conventional steel sheet. Nowadays, for this reason, it is usually applied more than 20 percentage of overall steel sheet used in the commercial car. Owing to these special mechanical properties, however, they prevented many conventional sheet metal forming processes from being suitably applied for high-strength steel sheet to fabricate the automotive part. For example, in terms of blanking process, many researches illustrated that the recommended blanking clearance commonly applied for conventional steel sheet is not suitable for applying in blanking process of high-strength steel sheet $[1,2]$. It is also suggested that the suitable blanking clearance applied for high-strength steel sheet should be larger, and it was recommended of approximately $10-20 \%$ thickness [2]. Next, in terms of forming process, many past researches confirmed that the springback characteristics of high-strength steel sheet were different from that of conventional steel sheet, thereby the conventional bending process is not suitable for springback control of bent high-strength steel parts [3]. In addition, the development of improving of high-strength steel sheet properties is continuously carried out to serve the more requirements in automotive industry [4]. These have pushed a high corresponding development of advanced technologies for sheet metal forming process to serve the fabrication of high-strength steel automotive parts. However, especially for precision sheet metal forming process, the past researches were not enough to understand the interaction between materials of workpiece and the tool as well as the effect of process parameters when improving efficiency of process and product quality. Furthermore, most of them were performed on forming process such as bending, flanging, and deep drawing processes $[3,5,6]$. There are a few researches carried out on precision shearing and blanking processes $[1,5,7]$. For these reasons, in the present study, the shaving process which is one of the precision sheet metal die cutting processes and which could produce the smooth cut surface overall material thickness was investigated by the experiments to examine the feasibility of this process applied for high-strength steel sheets. The results showed that the 


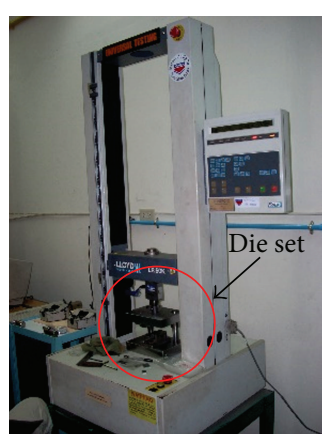

(a-1) Universal testing machine

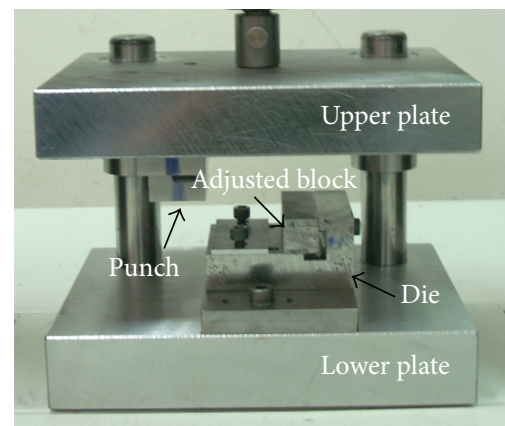

(a-2) Details of die set

(a) Press machine and die set

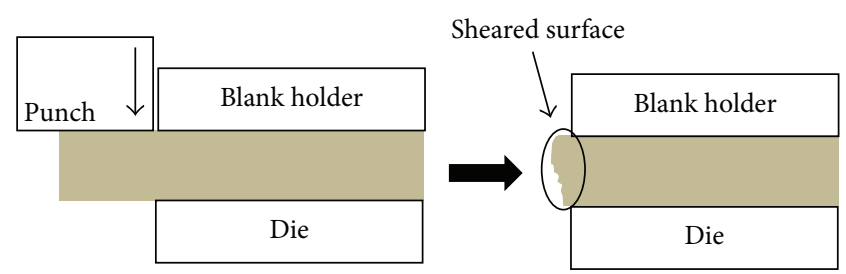

(b-1) Shearing process

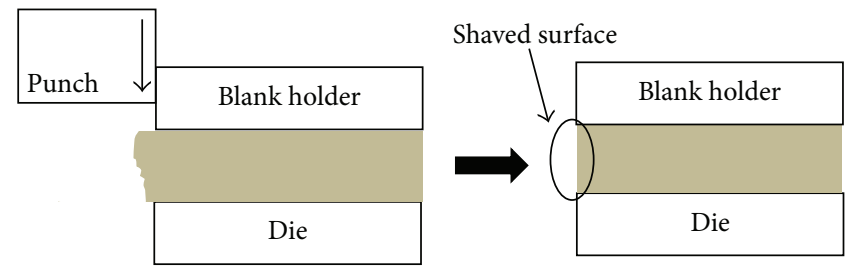

(b-2) Shaving process

(b) Principle of shaving process

FIGURE 1: Experimental equipment and principle of shaving process.

shaving process could not be applied to fabricate the smooth cut surface overall material thickness on high-strength steel sheets.

\section{Experimental Procedures}

The materials used, in the present study, were 2 types of high-strength steel sheets of SAPH 440 (JIS) and SPFH 590Y (JIS). In addition, the materials of aluminum sheets (A1100$\mathrm{O}(\mathrm{JIS})$ ) and carbon steel sheets (SPCC (JIS)) were also used as a conventional metal sheet to be compared with the high-strength steel sheets. The chemical compositions and mechanical properties of SAPH 440, SPFH 590Y, A1100$\mathrm{O}$, and SPCC are listed in Tables 1 and 2, respectively. The experimental equipment including the universal testing machine used as press machine and die set used for the experiments in the present study is shown in Figure 1(a). Next, as shown in Figure 1(b), the experimental model was illustrated. The shearing operation was first performed to predict cut edge geometries, as shown in Figure 1(b-1). Next, the sheared parts were again shaved by the shaving operation, as shown in Figure 1(b-2). As listed in Table 3, the shearing operation was performed with a $30 \mathrm{~mm}$ workpiece width and a $2 \mathrm{~mm}$ workpiece thickness at the clearance of 5,10 , and $20 \%$ of the workpiece thickness. The shaving operation was carried out using a shaving clearance of $0 \%$ of the workpiece thickness with four levels of $0.1,0.3,0.5$, and $1.0 \mathrm{~mm}$ shaving allowance. The tool cutting edge radii were set at $0.01 \mathrm{~mm}$ on punch and die for both shearing and shaving processes. First, by using the optical microscopy, the workpiece was sheared and the sheared surface feature including die-roll, smooth cut surface, and cracks was observed, as shown in Figure 1(b-1). Next, as the second operation of shaving step, the shaving clearance of $0 \%$ of the workpiece thickness was adjusted as well as the shaving allowance which was also adjusted by setting the moving plate. The sheared workpiece was again shaved, and the shaved surface feature including die-roll, smooth cut surface, and cracks was observed by the optical microscopy as well, as shown in Figure 1(b-2). In the present study, five samples were investigated. The cut surface feature of die-roll, smooth cut, and crack was measured at five observation points in each sample.

\section{Results and Discussion}

3.1. Comparison of the Sheared Surface Feature in the Shearing Process. Figure 2 shows the comparison of the sheared surface feature in the shearing process regarding the shearing clearance. In terms of high-strength steel sheets, the results illustrated that as the shearing clearance increased, the amount of die-roll increased and the crack formations decreased, whereas the smooth cut surface was somewhat constant. These manners generally confirmed the agreement with the literature [6]. Comparing with the conventional metal sheet of A1100-O and SPCC, it was observed that the results of high-strength steel sheets were against those results of the conventional metal sheet of A1100-O and SPCC. Specifically, in terms of aluminum and carbon steel, the smooth cut surface decreased and again increased as the shearing clearance increased. The results illustrated that, in the shearing process, the relationship between sheared surface feature and shearing clearance of high-strength steel sheets was against the theory of the basic shearing process of conventional metal sheet from the literature. In the present study, for SAPH 440 , as the shearing clearances were $5 \% t$, $10 \% t$, and $20 \% t$, the amounts of die-roll were $0.24 \mathrm{~mm}$, $0.27 \mathrm{~mm}$, and $0.28 \mathrm{~mm}$, respectively. Next, for SPFH 590Y, they were $0.15 \mathrm{~mm}, 0.19 \mathrm{~mm}$, and $0.23 \mathrm{~mm}$, respectively, Also, for SAPH 440, the smooth cut surface and crack were $0.35 \mathrm{~mm}$ and $1.41 \mathrm{~mm}, 0.35 \mathrm{~mm}$ and $1.38 \mathrm{~mm}$, and $0.37 \mathrm{~mm}$ and $1.34 \mathrm{~mm}$, respectively, as the shearing clearance were $5 \% t, 10 \% t$, and $20 \% t$. Again, for SPFH 590Y, the smooth 
TABLE 1: Chemical composition of materials.

\begin{tabular}{|c|c|c|c|c|c|c|c|c|c|c|c|c|c|}
\hline \multirow{2}{*}{ Material } & \multicolumn{13}{|c|}{ Chemical compositions (\%) } \\
\hline & Mn & $\mathrm{Fe}$ & $\mathrm{Si}$ & $\mathrm{P}$ & $\mathrm{C}$ & S & $\mathrm{Cr}$ & $\mathrm{Cu}$ & Mo & $\mathrm{Ni}$ & $\mathrm{Zn}$ & $\mathrm{Al}$ & $\mathrm{Mg}$ \\
\hline SAPH 440 & 1.026 & 98.712 & 0.050 & 0.011 & 0.126 & 0.003 & 0.022 & 0.020 & 0.012 & 0.018 & - & - & - \\
\hline SPFH 590Y & 0.352 & 93.678 & 0.791 & 0.021 & 0.350 & 0.012 & 4.796 & - & - & - & - & - & - \\
\hline SPCC & 0.440 & 99.285 & - & 0.101 & 0.131 & 0.043 & - & - & - & - & - & - & - \\
\hline Al1100-O & 0.050 & 0.615 & 0.100 & - & - & - & 0.010 & 0.100 & - & - & 0.050 & 99.000 & 0.075 \\
\hline
\end{tabular}

TABLE 2: Mechanical properties of workpiece material.

\begin{tabular}{lccc}
\hline Material & $\begin{array}{c}\text { Yield stress } \\
(\mathrm{MPa})\end{array}$ & $\begin{array}{c}\text { Tensile } \\
\text { strength } \\
(\mathrm{MPa})\end{array}$ & Elongation (\%) \\
\hline Al1100-O & 88.00 & 105.00 & 30.00 \\
SPCC & 210.10 & 310.50 & 46.95 \\
SAPH 440 & 340.05 & 461.18 & 33.83 \\
SPFH 590Y & 481.12 & 614.97 & 25.98 \\
\hline
\end{tabular}

TABLE 3: Experimental conditions.

\begin{tabular}{|c|c|}
\hline Punch, die & SKD 11 (60 HRC) \\
\hline Workpiece & Al1100-O, SAPH 440, SPFH 590Y, and SPCC \\
\hline \multirow{3}{*}{$\begin{array}{l}\text { Workpiece } \\
\text { dimension: } \mathrm{mm}\end{array}$} & Thickness: 2 \\
\hline & Width: 30 \\
\hline & Length: 70 \\
\hline $\begin{array}{l}\text { Shearing clearance } \\
\left(\mathrm{Cl}_{\mathrm{s}}\right): \% t\end{array}$ & 5,10 , and 20 \\
\hline $\begin{array}{l}\text { Shaving clearance } \\
\left(\mathrm{Cl}_{\mathrm{sh}}\right): \% t\end{array}$ & 0 \\
\hline $\begin{array}{l}\text { Shaving allowance } \\
\left(D_{\text {sh }}\right): \mathrm{mm}\end{array}$ & $0.1,0.3,0.5$, and 1.0 \\
\hline $\begin{array}{l}\text { Radius of cutting edge } \\
\left(R_{p}\right): \mathrm{mm}\end{array}$ & 0.01 \\
\hline
\end{tabular}

cut surface and crack were $0.43 \mathrm{~mm}$ and $1.42 \mathrm{~mm}, 0.46 \mathrm{~mm}$ and 1.35 , and $0.43 \mathrm{~mm}$ and $1.34 \mathrm{~mm}$, respectively, as the shearing clearance were $5 \% t, 10 \% t$, and $20 \% t$. Through these results, it was observed that the amounts of die-roll and smooth cut surface were, respectively, smaller and larger in the case of SPFH 590Y than those in the case of SAPH 440. In addition, it was also observed that, comparing with the conventional metal sheet of A1100-O and SPCC, the smooth cut surface was smaller in the case of high-strength steel sheets than those in the case of aluminum and carbon steel sheets. In addition, poor orthogonal cut surface was generated as the shearing clearance increased. Figure 3 shows an example of comparison of the sheared surface feature and poor orthogonal cut surface in the shearing process regarding the shearing clearance. As per the theory of the basic shearing process [8-10], the poor orthogonal cut surface was generated by shearing clearance. In the present study, the poor orthogonal cut surface were $0.10 \mathrm{~mm}, 0.20 \mathrm{~mm}$, and $0.40 \mathrm{~mm}$ in both cases of SAPH 440 and SPFH $590 \mathrm{Y}$ as the shearing clearance were $5 \% t, 10 \% t$, and $20 \% t$, respectively, which corresponded well with the basic shearing process from the literature [8-10].

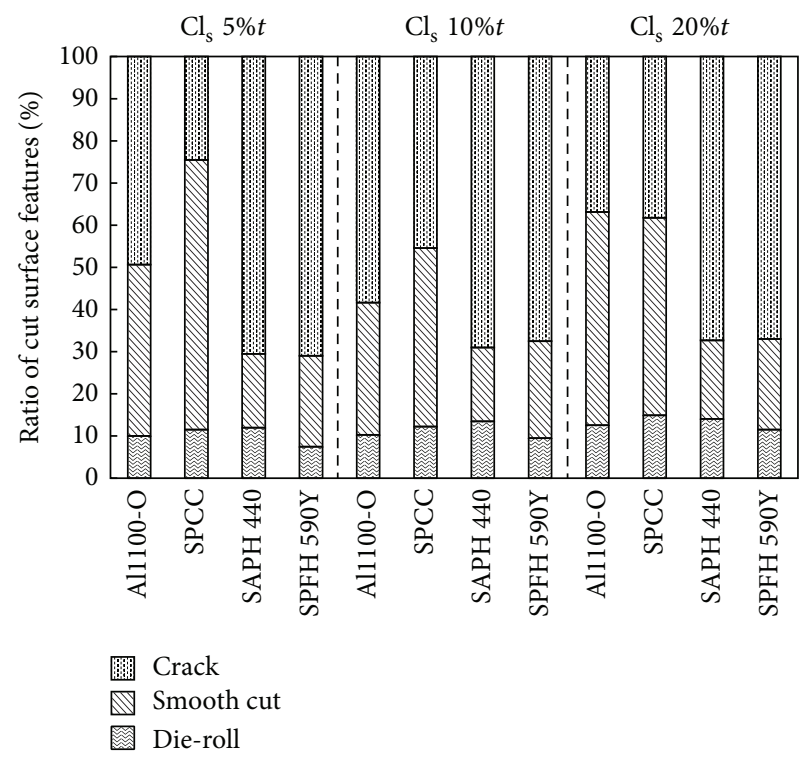

Figure 2: Comparison of cut surface after shearing process with respect to the shearing clearances.

\subsection{Comparison of the Shaved Surface Feature in the Shaving} Process. As the abovementioned sheared surface feature of high-strength steel sheets, the sheared surface feature with respect to shearing clearances was against those of aluminum sheets, as well as the basic shearing process from the literature [8-10]. As in the past researches [8], in terms of aluminum and carbon steel sheets, the shaving process could be applied to fabricate the smooth cut surface overall material thickness. Therefore, in the present study, the feasibility of this process applied for high-strength steel sheets was investigated. Figure 4 shows an example of comparison of the shaved surface feature in the shaving process regarding the shearing clearance and shaving allowance. The results showed that as the small shearing clearance and small shaving allowance were applied, the tearing was generated as shown in Figure 4(a). These manners generally confirmed the agreement with the theory of the shaving process of conventional metal sheet from the literature [8]. Next, as the shearing clearance increased, the tearing decreased as shown in Figure 4(b). However, it was also observed that the smooth cut surface decreased as well. Specifically, the crack formations were easily generated. These manners generally confirmed the agreement with the theory of the shaving process of conventional metal sheet from the literature [8]. As the shaving allowance increased as shown in Figure 4(c), the tearing could not be generated. However, with the large 


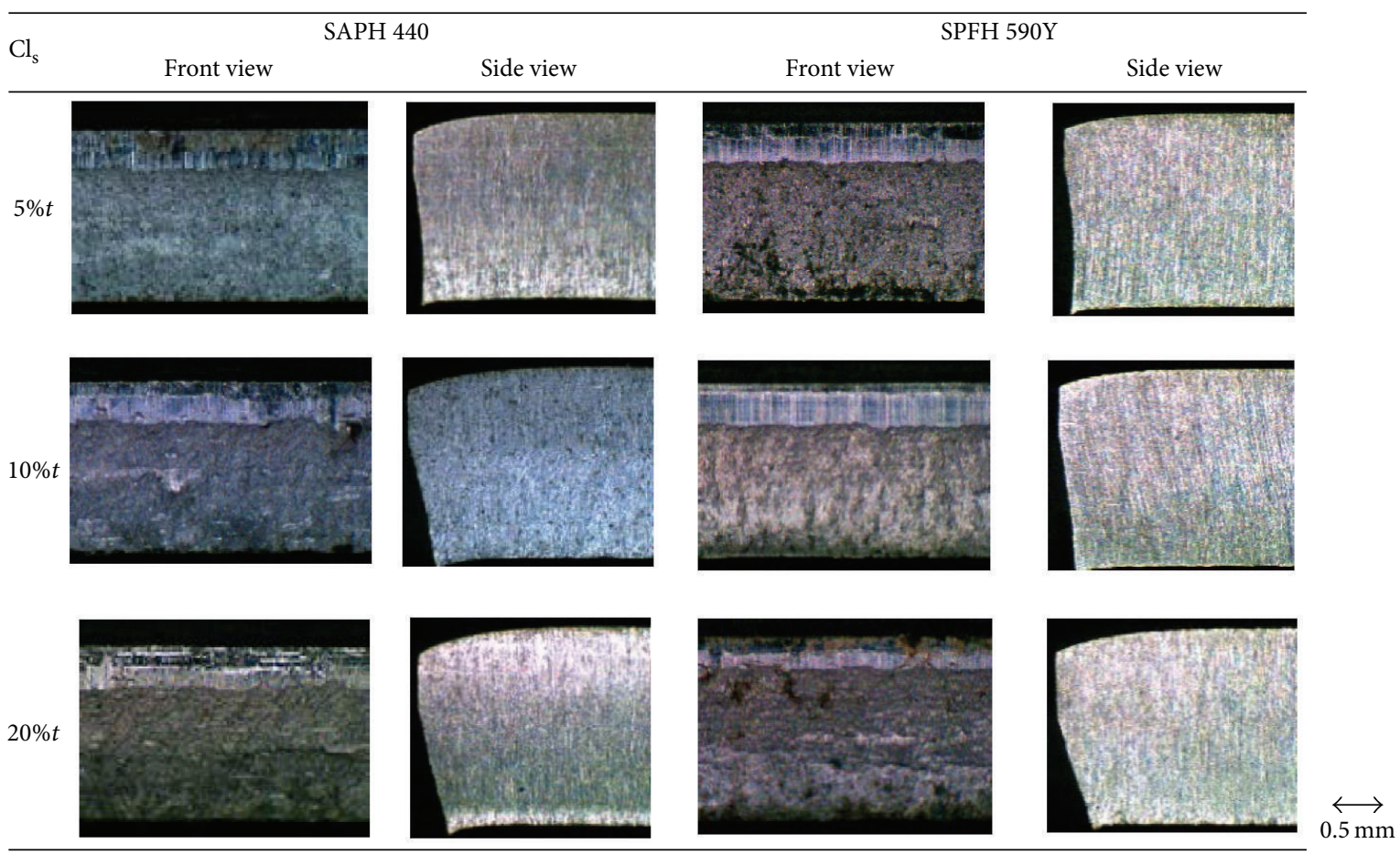

FIGURE 3: An example of cut surface after shearing process of high-strength steel sheet.

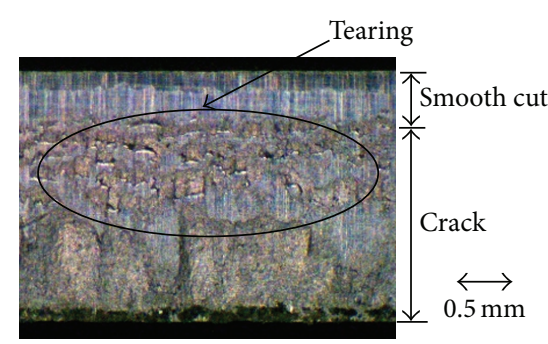

(a) $\mathrm{Cl}_{\mathrm{s}} 5 \% t, D_{\mathrm{sh}} 0.1 \mathrm{~mm}$

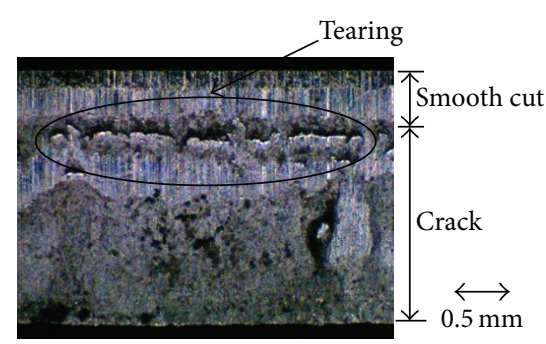

(b) $\mathrm{Cl}_{\mathrm{s}} 10 \% t, D_{\mathrm{sh}} 0.1 \mathrm{~mm}$

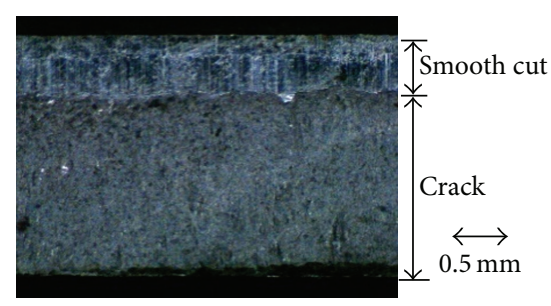

(c) $\mathrm{Cl}_{\mathrm{s}} 5 \% \mathrm{t}, D_{\mathrm{sh}} 1.0 \mathrm{~mm}$

FIGURE 4: An example of shaved surface of SAPH 440.

shaving allowance, the crack formations were easily generated and then the smooth cut surface decreased. Again, these manners generally confirmed the agreement with the theory of the shaving process of conventional metal sheet from the literature [8]. Figure 5 illustrates the relationship between shaved surface feature and shearing clearance. As the results show, the tendency of shaved surface feature of high-strength steel sheets corresponded well with that of aluminum and carbon steel sheets. Specifically, as the shearing clearance increased, the amount of die-roll increased but the smooth cut surface decreased. However, as aforementioned, it was observed that the tearing was generated as the shearing clearance of $5 \% t$ was applied. It was also noted that as comparing with aluminum and carbon steel sheets, the smooth cut surface of high-strength steel sheets were smaller than that of aluminum and carbon steel sheets. These results could be explained by the mechanical properties of material. Specifically, the mechanical property of ultimate tensile strength of high-strength steel sheets was larger than those of aluminum and carbon steel sheets. However, the results elucidated that the relationship between shaved surface feature and shearing clearance of high-strength steel sheets was well corresponded with those of conventional metal sheets from the literature [8-10]. Next, to obtain the smooth cut surface overall material thickness, the successful area of shaving conditions was investigated. As shown in Figure 6, the successful area for aluminum and carbon steel sheets could be found which corresponded well with the basic shaving process from the literature [8]. Specifically, as per the past research [8], the successful area could be found by applying shearing clearance smaller than $5 \% t$ with shaving allowances of $0.1 \mathrm{~mm}$. In the present study, the results showed the successful area of using shearing clearance of $5 \% t$ with shaving allowances of $0.1 \mathrm{~mm}$. However, it was interesting that the successful area could not be found for high-strength steel sheets. Therefore, through these results, this research revealed that, in terms of highstrength steel sheets, the shaving process could not be applied to fabricate the smooth cut surface overall material thickness. 


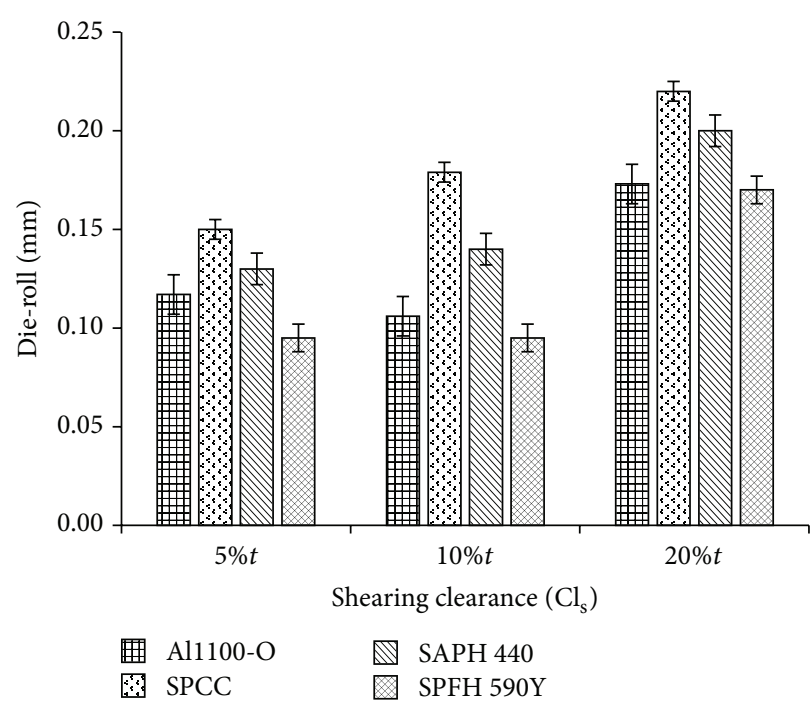

(a) Die-roll

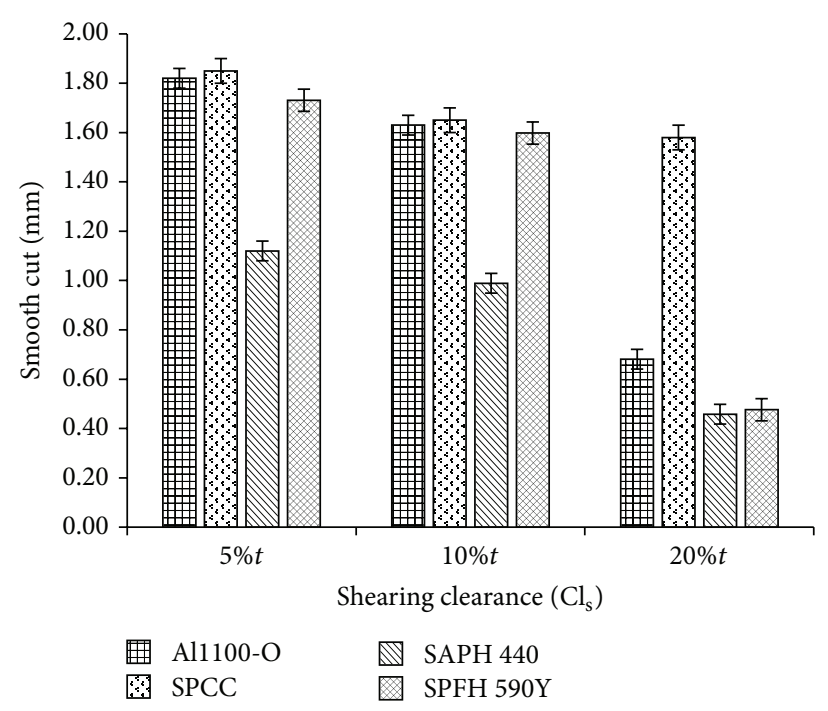

(b) Smooth cut

FIGURE 5: Relationship between shaved surface features and shearing clearances $\left(D_{\mathrm{sh}}: 0.1 \mathrm{~mm}\right)$.

\begin{tabular}{|c|c|c|c|c|c|c|c|c|c|c|c|c|c|c|c|c|}
\hline \multirow{3}{*}{$\mathrm{Cl}_{\mathrm{s}}$} & \multicolumn{16}{|c|}{$D_{\mathrm{sh}}(\mathrm{mm})$} \\
\hline & \multicolumn{4}{|c|}{ Al1100-O } & \multicolumn{4}{|c|}{ SPCC } & \multicolumn{4}{|c|}{ SAPH 440} & \multicolumn{4}{|c|}{ SPFH 590Y } \\
\hline & 0.1 & 0.3 & 0.5 & 1.0 & 0.1 & 0.3 & 0.5 & 1.0 & 0.1 & 0.3 & 0.5 & 1.0 & 0.1 & 0.3 & 0.5 & 1.0 \\
\hline $5 \% t$ & 0 & 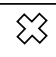 & $\aleph$ & 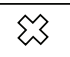 & 0 & 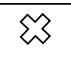 & $\S$ & 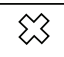 & $\sum_{(\mathrm{T})}$ & 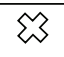 & 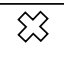 & 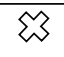 & $\hat{\Sigma}(\mathrm{T})$ & 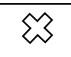 & 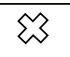 & 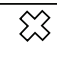 \\
\hline $10 \% t$ & 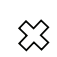 & 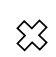 & 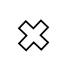 & $\aleph$ & 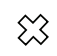 & 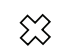 & 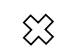 & 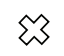 & $\aleph_{(\mathrm{T})}$ & 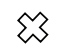 & 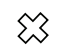 & 绽 & $\hat{\Sigma}(\mathrm{T})$ & 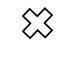 & $\aleph$ & 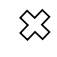 \\
\hline $20 \% t$ & $\lesssim$ & 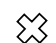 & $\lesssim$ & 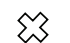 & $\lesssim$ & 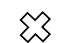 & 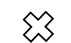 & 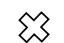 & $\lesssim$ & $\Sigma$ & 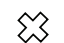 & 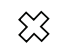 & 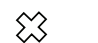 & 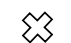 & 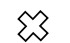 & $\lesssim$ \\
\hline
\end{tabular}

Figure 6: Successful ranges of shaving conditions.

\section{Conclusions}

In the present study, the feasibility of shaving process applied for high-strength steel sheets was investigated by using the experiments. The shearing process of high-strength steel sheets was performed as the first operation of shaving process. The sheared surface feature in this process was examined and compared with that of conventional metal sheet of aluminum and carbon steel. The results illustrated that, in the shearing process, the relationship between sheared surface feature and shearing clearance was well against the theory of the basic shearing process of conventional metal sheet from the literature. As the shearing clearance increased, the amount of die-roll increased, but the crack formation decreased, whereas the smoot cut surface was somewhat constant. In addition, poor orthogonal cut surface increasingly was generated as the shearing clearance increased. Next, in the shaving process, the relationship between shaved surface feature and shearing clearance confirmed the agreement with the theory of the shaving process of conventional metal sheet from the literature. As the shearing clearance increased, the amount of die-roll increased but the smooth cut surface decreased. In addition, the tearing usually was generated as the small shearing clearance and shaving allowance were applied. Although the relationship between shaved surface feature and shearing clearance of high-strength steel sheets confirmed the agreement with the theory of those of conventional metal sheet from the literature, the successful area of shaving process application on high-strength steel sheets could not be found. Through these results, it was revealed in the present study that, owing to the special mechanical properties of high-strength steel sheets, the shaving process could not be applied to fabricate the smooth cut surface overall material thickness. To fabricate the smooth cut surface overall material thickness, in the next future work, the new process should be invented.

\section{Competing Interests}

The authors declare that they have no competing interests.

\section{Acknowledgments}

This research was partially supported by the Higher Education Research Promotion and National Research University 
Project of Thailand, Office of the Higher Education Commission, under Grant no. 56000519 and Grant no. 57000618.

\section{References}

[1] M. Feistle, R. Golle, and W. Volk, "Determining the influence of shear cutting parameters on the edge cracking susceptibility of high-strength-steels using the edge-fracture-tensile-test," Procedia CIRP, vol. 41, pp. 1078-1083, 2016.

[2] K. Mori, Y. Abe, Y. Kidoma, and P. Kadarno, "Slight clearance punching of ultra-high strength steel sheets using punch having small round edge," International Journal of Machine Tools and Manufacture, vol. 65, pp. 41-46, 2013.

[3] X. Yang, C. Choi, N. K. Sever, and T. Altan, "Prediction of springback in air-bending of Advanced High Strength steel (DP780) considering Young's modulus variation and with a piecewise hardening function," International Journal of Mechanical Sciences, vol. 105, pp. 266-272, 2016.

[4] A. G. Kalashami, A. Kermanpur, A. Najafizadeh, and Y. Mazaheri, "Development of a high strength and ductile Nb-bearing dual phase steel by cold-rolling and intercritical annealing of the ferrite-martensite microstructures," Materials Science and Engineering A, vol. 658, pp. 355-366, 2016.

[5] K. Mori, S. Maki, and Y. Tanaka, "Warm and hot stamping of ultra high tensile strength steel sheets using resistance heating," CIRP Annals-Manufacturing Technology, vol. 54, no. 1, pp. 209-212, 2005.

[6] K. Mori, Y. Abe, and Y. Suzui, "Improvement of stretch flangeability of ultra high strength steel sheet by smoothing of sheared edge," Journal of Materials Processing Technology, vol. 210, no. 4, pp. 653-659, 2010.

[7] M. Murakawa, K. Nakamura, T. Shionome, F. Komuro, G. Muro, and N. Koga, "Press-shaving characteristics of ultrahighstrength steel sheets," Key Engineering Materials, vol. 554-557, pp. 1879-1886, 2013.

[8] M. Murakawa, S. Thipprakmas, and M. Jin, "Investigate of relationship between shaved surface and shaving allowance," Journal of Japan Society for Technology of Plasticity, vol. 44, no. 513, pp. 53-57, 2003 (Japanese).

[9] S. Thipprakmas, W. Phanitwong, M. Chinwithee, and T. Morkprom, "Reciprocating shaving approach to eliminate crack and burr formation in pressed parts," Key Engineering Materials, vol. 443, pp. 217-224, 2010.

[10] S. Thipprakmas and W. Phanitwong, "Finite element analysis of shaving direction effects in reciprocating shaving process," Steel Research International, vol. 81, no. 9, pp. 1058-1061, 2010. 

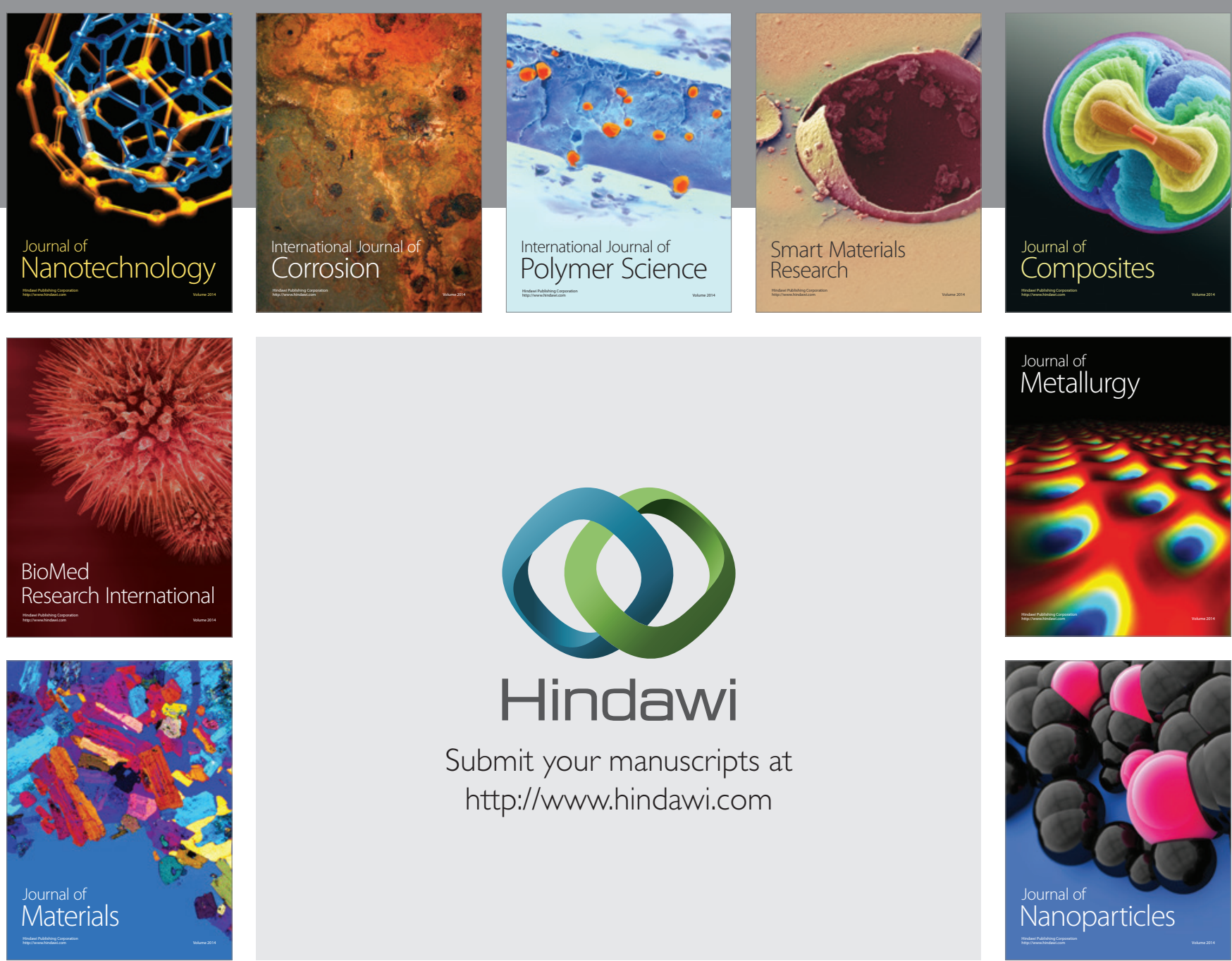

\section{Hindawi}

Submit your manuscripts at

http://www.hindawi.com

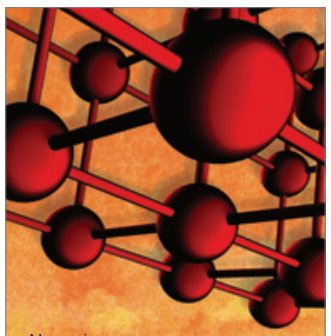

Materials Science and Engineering
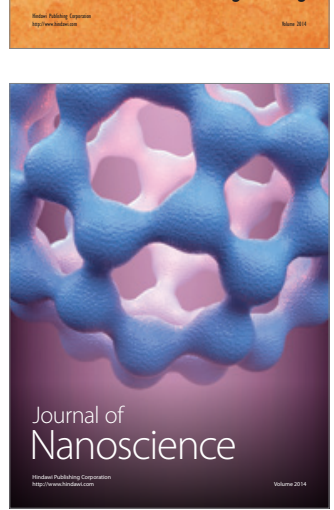
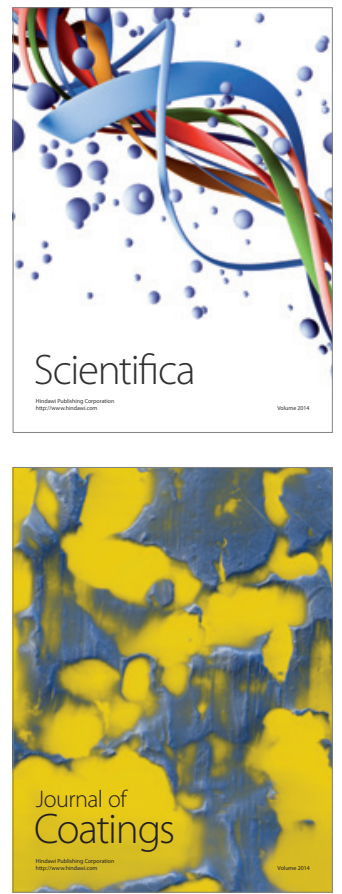
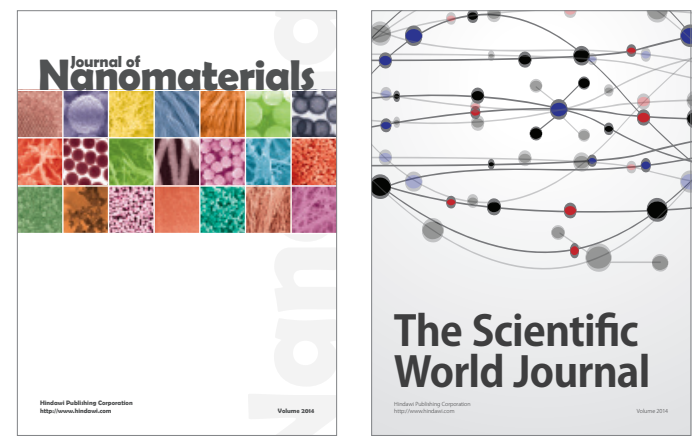

The Scientific World Journal
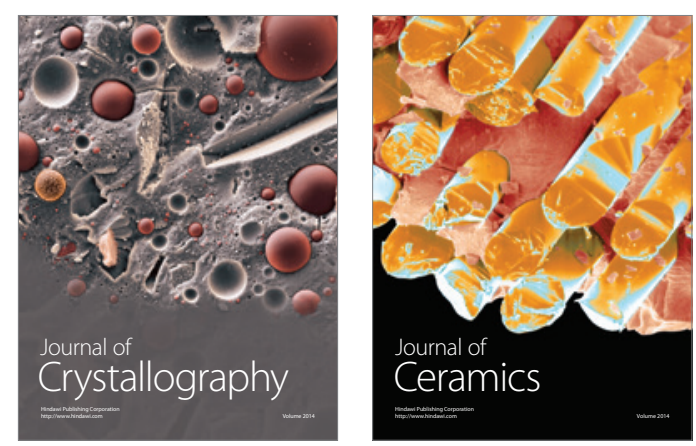
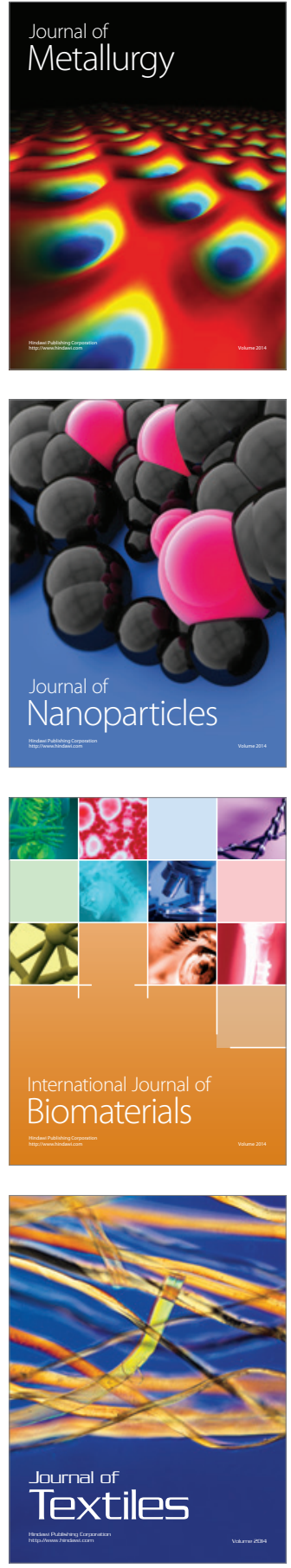